\title{
NOSTALGIAS, CONVERSIONES Y DESBORDES EN SAN PEDRO DE ATACAMA
}

\section{Nostalgies, Conversions and Overflows in San Pedro de Atacama}

\section{RAÚL MOLINA*}

Fecha de recepción: 25 de mayo de 2019 - Fecha de aprobación: 15 de noviembre de 2019

\section{Resumen}

El presente ensayo etnográfico da cuenta de los cambios, los conflictos, las colonizaciones y las invasiones provocadas por la acelerada expansión turística ocurrida en las últimas décadas en San Pedro de Atacama. Describe los impactos que ha generado el turismo en el casco histórico del pueblo, la gentrificación rural de los ayllus y la invasión de los territorios de las comunidades atacameñas en la cuenca del salar de Atacama. Las nostalgias abordan lo que fue este oasis del desierto, las conversiones tratan de los impactos y las colonizaciones, los desbordes se presentan en la expansión urbana, la desregulación turística y la invasión territorial de los tours operadores. Todo lo anterior cruzado por el ocultamiento de la cultura e historia atacameña en un territorio colonizado por el turismo.

Palabras clave: San Pedro de Atacama; turismo; gentrificación rural; colonización; territorios indígenas.

\section{Abstract}

This ethnographic essay gives an account of the changes, conflicts, colonizations and invasions caused by the accelerated tourist expansion that has occurred in recent decades in San Pedro de Atacama. It describes the impacts that tourism has generated in the historic center, the rural gentrification of the ayllus and the invasion of the territories of the Atacamenian communities in the Salar de Atacama basin. Nostalgic addresses what this desert oasis was, conversions deal with impacts and colonizations. The overflows are represented by urban expansion, tourist deregulation and territorial invasion of tour operators. All of the above crossed by the concealment of the Atacamenian culture and history in a territory colonized by tourism.

Keywords: San Pedro de Atacama; tourism; rural gentrification; colonization; indigenous territory.

* Geógrafo. Dr. en Antropología. Proyecto Fondecyt № 1170236, Centro de Estudios Interculturales e Indígenas (CIIR), Santiago de Chile. Correo-e: raul17molina@gmail.com 


\section{Introducción}

Con el paso del tiempo, San Pedro de Atacama pertenece cada vez menos a los atacameños. Poco a poco, sus antiguos habitantes se adaptan a un pueblo que se ha ido convirtiendo en un lugar extraño, transfigurado por la sistemática colonización del turismo, desarrollado con la anuencia y/o la participación de los mismos atacameños. Aunque los cambios en la zona de San Pedro de Atacama no son nuevos, pues han ocurrido desde los periodos precolombinos, pasando por las etapas colonial y republicana (Núñez, 1992), la fase actual de transformaciones se caracteriza por la rápida expansión e impacto del turismo y por el constante arribo de miles de turistas a lo largo del año. Este fenómeno ha sido acompañado de nuevos procesos de urbanización, copamiento comercial del centro del pueblo, pérdida de tierras indígenas y gentrificación rural (Sepúlveda, Molina, Delgado-Serrano \& Guerrero, 2015; Molina, 2018a, 2018b). En suma, es posible observar a San Pedro de Atacama como un lugar colonizado por la industria turística1. Pero los impactos no solo se localizan en San Pedro de Atacama y sus ayllus, sino también en muchos otros lugares de la cuenca del salar de Atacama, pues los destinos turísticos están polilocalizados en los territorios de las comunidades atacameñas.

La rápida expansión del turismo se ha alimentado de un fenómeno conocido como "turistificación" (Oehmichen y De la Maza, 2019) que consiste en que casi todo emprendimiento de la población local se piensa vinculado a la actividad turística y destinado a satisfacer lo que "busca y quiere el turista". Así, muchos atacameños especulan y cavilan sobre cómo adaptarse y/o insertarse en esta pujante actividad que consume, preferentemente, paisajes y experiencias estéticas relacionadas con la geografía, donde la cultura y la historia del pueblo atacameño han quedado desplazadas e invisibilizadas. También la expansión turística ha provocado en algunas comunidades conatos de rechazo debido a las invasiones, la reiterada violación de la privacidad y de las formas de vida indígena, acompañadas de conductas no ecológicas de algunos visitantes, comportamientos que pueden conducir a la aparición de la "turismofobia" (García, Guitart, Pitarch y Vallvé, 2018; Milano, 2018), un síntoma social de animadversión hacia los turistas y a las empresas dedicadas a esta rentable actividad ${ }^{2}$.

\section{Nostalgias y conversiones}

Actualmente, San Pedro de Atacama solo conserva la apariencia de antaño en su casco histórico central o down town, manteniendo un estilo arquitectónico de casas de adobes. La mayoría de estas viviendas se han convertido en lugares no habitados por sus antiguos moradores, quienes han cedido los espacios domésticos y comunitarios para la instalación de hoteles, restaurantes, tiendas de artesanía, cajeros automáticos de bancos, tiendas de ropa outdoor, agencias de turismo, farmacias y galerías comerciales, entre otras. Estos inmuebles, ubicados en el centro histórico, son regentados por empresas y personas no atacameñas, que han comprado la propiedad o la arriendan con importantes sumas de capital a personas a los antiguos moradores. Solo unos pocos atacameños conservan sus antiguas moradas y otros han convertido sus casas y terrenos urbanos en espléndidos hoteles o en modestos alojamientos. Los menos conservan sus viejos 
almacenes que abastecen a cientos de turistas que deambulan de arriba a abajo por estas calles del down town pueblerino, el área central urbana más beneficiada por la pujanza económica de la expansión y la invasión turística ${ }^{3}$.

El down town sanpedrino alberga en la actualidad gran parte de las 110 oficinas de empresas de tours operadores inscritas en 2017 en el Servicio Nacional de Turismo (SERNATUR). También concentra casi cien restaurantes, 73 de ellos catastrados en internet (Molina, 2018a), y algunos de los 98 establecimientos hoteleros y de alojamiento que existían hasta el año 2012. Según cifras extraoficiales de estudios de la Municipalidad de San Pedro de Atacama, en el año 2019 los sitios de hospedaje de distinto tamaño y calidad superan los 350 establecimientos, localizados en el pueblo y en los ayllus cercanos. Lejos en el tiempo y superada por la expansión hotelera quedó la antigua Hostería de San Pedro de Atacama, hoy Hotel Diego de Almagro, construida en la década de 1970, y las dos o tres pensiones que existían en el pueblo en la década de 1980 (Molina, 2018b).

La afluencia de turistas ha convertido a San Pedro de Atacama en un lugar dormitorio para visitantes nacionales y extranjeros. De allí el gran número de hoteles y restaurantes que es posible encontrar en sus calles. En 2016 ingresaron 156.478 turistas, de los cuales $30 \%$ (49.013 personas) eran nacionales y $70 \%$ (107.464 personas) extranjeros (SERNATUR, 2017). Estas cifras se han incrementado en los últimos años. Según estos datos, los turistas se quedan un promedio de 2,78 días. La afluencia de visitantes en 2106 alcanzó un promedio de 13 mil personas al mes, aunque su concentración aumenta o disminuye de acuerdo con las temporadas altas y bajas, y el calendario de vacaciones y feriados nacionales y extranjeros ${ }^{4}$.

Ahora bien, la afluencia de turistas, así como la infraestructura y los servicios creados en torno al turismo constituyen una nueva forma de colonización económica y sociocultural, la cual desde hace unas décadas ha estado metarmorfizando al antiguo y bucólico San Pedro de Atacama y sus ayllus, pueblo que alguna vez tuvó una impronta agrícola y pastoril (Aranda, 1964; Núñez, 1992; Rivera, 1995; Gundermann \& González, 1995; Gundermann, 2004; Vilches, Sanhueza \& Garrido, 2014). A los ojos del visitante ya no existen ni aparece el atacameño y su cultura, ni siquiera es posible observar el ganado ovino que alguna vez fue arreado por las calles del poblado. La artesanía local fue reemplazada por la factura industrial con motivos "andinos" importada de China, Perú y Bolivia. Hoy solo es posible encontrar en algún puesto en la feria artesanal o en una que otra tienda algunos productos locales de tipo culinario, como harinas y arropes de chañar y algarrobo, y pequeñas figuras en piedra volcánica de Toconao y en madera de cactus.

La mayoría de los atacameños no tiene presencia pública en las zonas turísticas de San Pedro de Atacama, ya sea porque se han refugiados en las últimas tierras de los ayllus o se han radicados en las nuevas poblaciones construidas en los márgenes de San Pedro de Atacama. Los atacameños como mano de obra, se insertan como trabajadores de servicio en hoteles y restoranes. Mientras tanto los turistas se pasean por el centro histórico y observan un pueblo de arquitectura tradicional, de calles de tierra, comercio urbano, ofertas turísticas y a cientos de visitantes que como ellos mismos 
deambulan por este oasis repleto de añosos algarrobos y tamarugos. Los paseantes que se concentran en el boulevard de calle Caracoles muchas veces son interrumpidos en su camino por las ofertas de los hunters, jóvenes migrantes nacionales que se enrolan en estos trabajos ocasionales para ofrecer comida en restaurantes o captar clientes para los tours operadores. Todo esto es parte del paisaje de la cotidianeidad sanpedrina. El pueblo y sus ayllus soportan esta carga turística y parecieran tener una resiliencia que les ha permitido conservar aún el carácter acogedor del oasis tradicional al que se arriba luego de recorrer extensas distancias por uno de los desiertos más áridos del planeta. Los que llegan a San Pedro de Atacama lo hacen para visitar los atractivos que ofrece la geografía y para encontrarse con los lugares construidos en su imaginario en las búsquedas en internet o por las ofertas de los hoteles y tours operadores. Estos últimos controlan los destinos y la movilidad en estos ignotos parajes ofertados.

Sin embargo, San Pedro de Atacama, pese a la invasión y la masividad del turismo, sigue conservando cierto encanto. Quizás porque aparentemente el desierto y el paisaje aún no han sido colonizados del todo, pues sus volcanes tutelares son muy altos y se yerguen como telón de fondo, o los oasis del ayllu con sus bosques y campos regados constituyen todavía un reparo para el sol brillante y el inmenso cielo azul, y protegen a los turistas de la sequedad inmensa del desierto. El down town pueblerino y los ayllus inmediatos forman una zona de refugio y bienestar, con todos los servicios básicos y comerciales para el visitante. Solo en los márgenes de este oasis de San Pedro de Atacama asoma el salar, el desierto, y más allá la imponente y amplia vista de las montañas, cuyas características ecológicas los mantienen a resguardo de la habitabilidad. Pero a la salida norte y oriente del pueblo, sobre el desierto, ya se pueden apreciar las extensas poblaciones de viviendas básicas, algunas muy precarias, que han desbordado el área urbana tradicional y que se expanden más allá de los límites del bucólico poblado histórico.

\section{Gentrificación hotelera y ventas de tierras en los ayllus}

Fuera del damero central e histórico de San Pedro de Atacama, formado sobre el antiguo ayllu de Conde Duque, existen otros diecinueve ayllus: Cuchabrache, Suchor, Bellavista, Guachar, Tambillo, Catarpe, Quitor, Solcor, Yaye, Larache, Checar, Séquitor, Coyo, Tulor, Vilama, Solor, Cúcuter, Poconche y Beter, distribuidos a lo largo de 14 kilómetros entre Cuchabrache por el norte y Tulor por el sur (Aedo, 2011). Estos ayllus, más que tierras pertenecientes a un grupo de parentesco, corresponden a oasis regados por los canales de los ríos Vilama y San Pedro (Aranda, 1964; Aranda, Barahona \& Saa, 1968; Sepúlveda, et al., 2015). Pero ya nada es como era. Estas tierras tuvieron una época de esplendor cuando estaban dedicadas a los cultivos de alfalfa asociados a la pujanza de la arriería y cuando servían de corrales, alimentación y descanso para el ganado traído del noroeste argentino con destino a las salitreras y minas de cobre. Esta bonanza subsistió hasta 1955 aproximadamente (Cerri, 1993 [1903]; Cipolletti, 1984; Conti, 2003; García, Rolandi, López \& Valeri, 2002; Gundermann, 2004; Molina, 2011, 2013; Vilches, et al., 2014). Durante la década de 1960 
el Estado se esmeró en mejorar el sistema de riego para incrementar su eficiencia y aumentar la superficie regada. Entre los atacameños los cultivos de esos años eran la alfalfa, el maíz y los cereales, asociados a una ganadería de subsistencia. La actividad agrícola se complementaba con el trabajo asalariado en las minas de cobre de Chuquicamata y con la migración laboral a las provincias trasandinas de Jujuy y Salta (Aranda, et al., 1968; Núñez, 1992).

Las tierras de los ayllus de San Pedro de Atacama fueron entregadas entre los años 1964 y 1966 mediante títulos gratuitos del Ministerio de Tierras y Colonización. Un informe ministerial señala que durante este periodo se otorgaron 815 títulos y se constituyeron 612 propiedades en San Pedro de Atacama, además de 41 propiedades en Quitor y 162 propiedades en Solor (CINPRO Consultores, 1997). Sin embargo, estas tierras perdieron la función productiva de antaño y han sido vendidas en gran proporción a empresas turísticas y particulares.

En el presente un porcentaje importante de las tierras atacameñas ya no le pertenece a sus habitantes ancestrales. Han sido enajenadas y se han convertido en el sostén material de la expansión del turismo o se han transformado en sitios residenciales para los nuevos pobladores rur-urbanos llegados desde fuera de San Pedro de Atacama. Las empresas hoteleras han acaparado un importante porcentaje de estas tierras en los ayllus de Conde Duque (lugar histórico del pueblo y su iglesia), Yaye, Sequitor, Larache y Quitor. En estos ayllus se ha intensificado el traspaso de la propiedad atacameña a particulares. Consecuente con ello ha ocurrido el cambio de uso del suelo agrícola a residencial-turístico (Bolados, 2014) ${ }^{5}$.

Actualmente en las calles de estos ayllus, especialmente en Domingo de Atienza, Calama, Tocopilla y Caracoles, es posible apreciar grandes hoteles como Tulor, Altiplánico, Kimal, Awasi, San Sebastián, Don Tomás, La Cochera, Takha Takha, Dunas, Cumbres, Tierra Atacama y el emblemático hotel Explora, que fue el símbolo del inicio del boom turístico ${ }^{6}$. Esta tendencia de expansión de la hotelería en tierras atacameñas ya era advertida en 2006 por la Municipalidad de San Pedro de Atacama, al señalar que las solicitudes de cambio de uso de suelos "tienen como fin último cambiar el destino de un predio agrícola a una actividad comercial derivada del turismo [...] la principal solicitud de cambio de destino se registra en el rubro hotelero, la situación se presenta solo en la Localidad de San Pedro de Atacama y las solicitudes de cambio de uso de suelos afectan a los Ayllos"(I.M. San Pedro de Atacama, Pladeco 2006, 5). 
Figura 1. Grandes hoteles en San Pedro de Atacama: Explora, Tierra Atacama, Alto Atacama, Kunsa y Awasi.
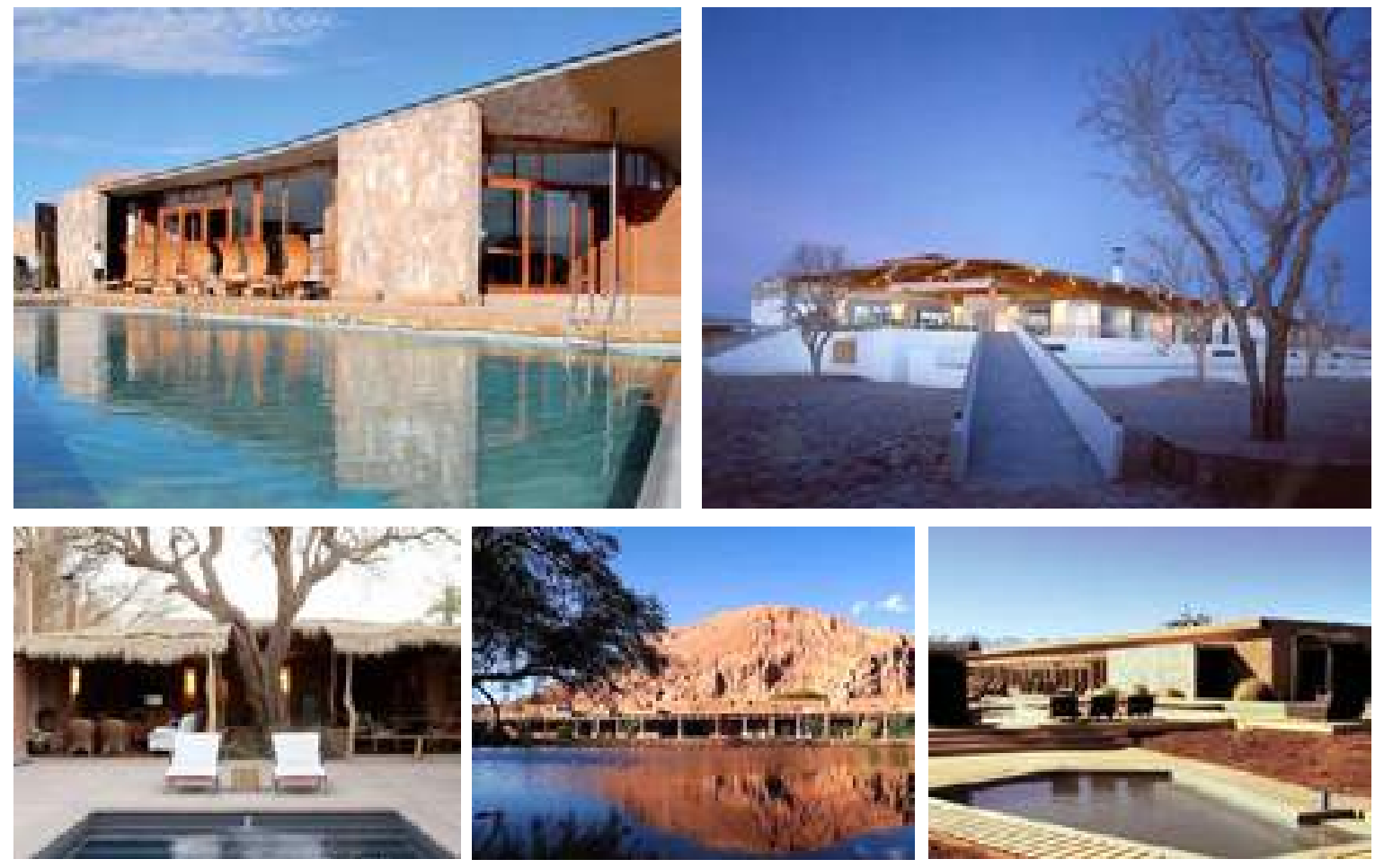

Fotografías publicadas en El Chululo (2011a).

Las tierras atacameñas, a pesar de ser indígenas y estar protegidas por los artículos 12, 13, 14 y 15 de la Ley Indígena 19.253, han sido vendidas por sus propietarios atacameños. La Corporación Nacional de Desarrollo Indígena (CONADI), ha carecido de una política de protección de estas tierras indígenas al permitir que el mercado opere libremente. La venta sistemática de terrenos ha provocado, desde hace dos a tres décadas, un proceso de "gentrificación rural" que consiste en la pérdida patrimonial de la propiedad agrícola. Los nuevos propietarios son mayoritariamente empresarios hoteleros, personas naturales y otras empresas. Las numerosas enajenaciones que se han podido verificar en la notaría y el Conservador de Bienes Raíces de la ciudad de Calama confirman que los atacameños y el Estado han mantenido abierto un activo mercado de tierras indígenas.

Paradójico resulta analizar una reciente demanda judicial efectuada en 2017 por un ex propietario de tierras del ayllu de Beter en contra de la empresa Valles del Sur S.A ${ }^{7}$. Esta empresa es la beneficiaria de la Fundación Tata Mallku, propiedad de una de las descendientes del fundador del retail Fallabella, que instaló en el ayllu de Beter un centro de formación, destinado a promover "la interculturalidad, fomentando la enseñanza, promoción y valorización de las tradiciones de nuestros ecosistemas (sic)"8. El ex propietario atacameño accionó 
ante la justicia contra Valles del Sur S.A. no para recuperar las tierras ancestrales, sino para alcanzar un mejor precio. La demanda fue una queja financiera, pero no una defensa de la "Pachamama". Atrás quedaron los líderes que durante la emergencia de la identidad étnica, a inicios de los años noventa, abogaban por el territorio y la autonomía, y lejos quedó la convicción de mujeres como Amelia Mamani Charcas y Sonia Ramos Chocobar, que defendieron la Pachamama caminando desde San Pedro de Atacama hasta la ciudad de Santiago en $2009^{9}$.

Figura 2. Felicidad de los integrantes de la Fundación Tata Mallku en su sede del ayllu de Beter.

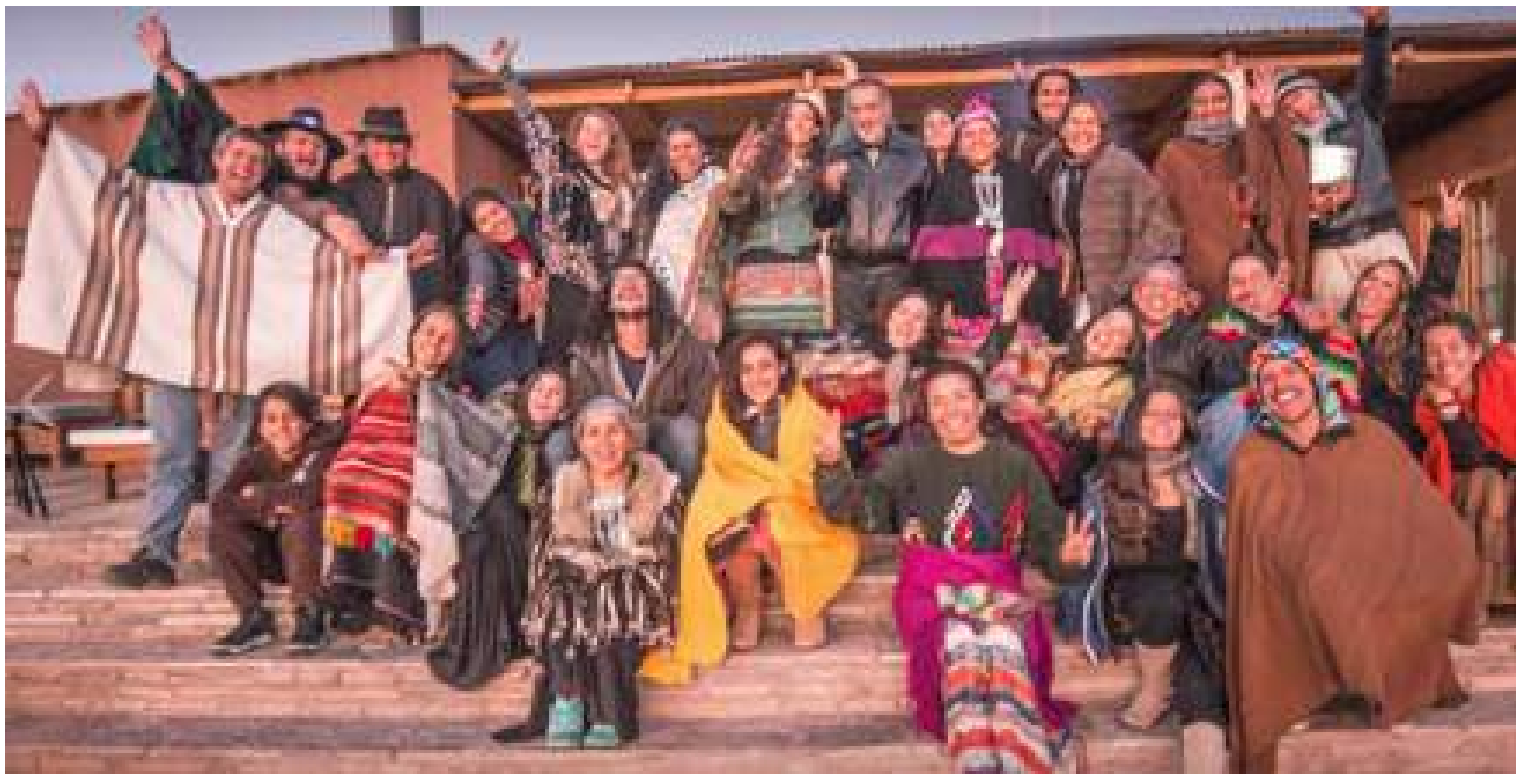

Fotografía: El Desconcierto (Figueroa, 2018).

\section{Crecimiento de población y expansión urbana sobre tierras del desierto}

Atrás quedó la antigua descripción de los ayllus de San Pedro de Atacama realizada en la década de 1980 por Lautaro Núñez (1992). El arqueólogo y premio nacional de historia describía a San Pedro de Atacama y sus ayllus como un lugar de larga historia y tradiciones, pero que desde la segunda mitad del siglo XIX y hasta la década de 1980 estaban siendo afectados por el despoblamiento por la migración hacia ciudades y centros mineros. Pese a ello, aún se conservaban antiguas prácticas agrícolas y ganaderas y sus tierras eran el refugio de jubilados que volvían a descansar después de trabajar en Chuquicamata y otros lugares. Otros autores se referían a San Pedro de Atacama del mismo modo, como un poblado rural dedicado a las actividades agrícolas y ganaderas (Gundermann \& González, 1995; Rivera, 1995; Sepúlveda, et al., 2015). 
Sin embargo, todo ello cambió. La matriz agroproductiva compuesta por la alfalfa, el maíz y el trigo se descompuso a partir de 1990. El trigo, en la práctica, ha desaparecido como cultivo y solo se conservan pequeñas superficies de maíz. La alfalfa, el cultivo más extendido y resistente, ha perdido su función de alimentar el ganado, pues el pastoreo ha tenido un radical descenso al alcanzar la masa ganadera su mínima expresión ${ }^{10}$. Además, disminuyeron el agua de riego y las superficies cultivadas. Los caudales de los ríos que riegan los ayllus decrecieron. El río San Pedro disminuyó su caudal medio anual de $1.127 \mathrm{l} / \mathrm{s}$ en 1940 a $620 \mathrm{l} / \mathrm{s}$ entre 2000 y 2014. En el caso del río Vilama, el caudal medio anual era de 332 l/s en la década de 1940, pero descendió a 76,7 l/s entre 2011 y 2014. La superficie cultivada descendió drásticamente de 1.210 hectáreas en 1964 a solo 709 hectáreas en 2014 (Sepúlveda, et al., 2015). Con el decaimiento de la actividad agrícola y ganadera atacameña se ha incrementado la venta de tierras para el turismo o para nuevos pobladores. El factor estructural que afecta la actividad agroganadera en San Pedro de Atacama se debe a la política de desarrollo agropecuario neoliberal, que ha marginado a los indígenas como actores productivos desconectados con el mercado exportador y alejados de las cadenas de transformación agroindustrial, obligándolos al abandono de la actividad agrícola por improductiva y económicamente insostenible.

El despoblamiento constante que caracterizó a San Pedro de Atacama hasta la década de 1980 comenzó a revertirse con el desarrollo turístico que detona en los noventa (Bustos 2005). En 1992 el Censo de Población arrojaba un total 1.473 habitantes en la comuna de San Pedro de Atacama, lo que incluía a todos los pueblos de la cuenca del salar. Diez años después, en el Censo de 2002, la población comunal se había incrementado a 4.969 habitantes, de los cuales 39\%, 1.938 personas, eran habitantes de San Pedro de Atacama. En 2012, la población comunal aumentó a 7.549 habitantes; en 2015 subió a 9.621 habitantes, lo que representa un crecimiento intercensal (2012-2015) de 27,5\% en la población permanente, y, finalmente, en el Censo de Población de 2017 se contabilizaron 10.996 personas a nivel comunal. Sobre este sostenido aumento podemos señalar que $80 \%$ de la población se concentra en San Pedro de Atacama. Este crecimiento se puede apreciar en el mayor número de viviendas a nivel comunal. En 2002 existían 2.067 viviendas, en 2012 habían aumentado a 3.129 y en 2017 habían 4.140. Este incremento urbano continúa en la actualidad, en especial en San Pedro de Atacama, donde han aparecido nuevas poblaciones y varias "tomas de terrenos" sobre tierras del desierto. 
Figura 3. Ingreso a San Pedro de Atacama desde Calama en los primeros años del siglo XXI. Se aprecian los ayllus con sus bosques y la cordillera de los Andes con sus volcanes. El paisaje de los ayllus aún representaba a un pueblo rural, donde no vivían más de 2.000 personas en la primera década del siglo XXI.

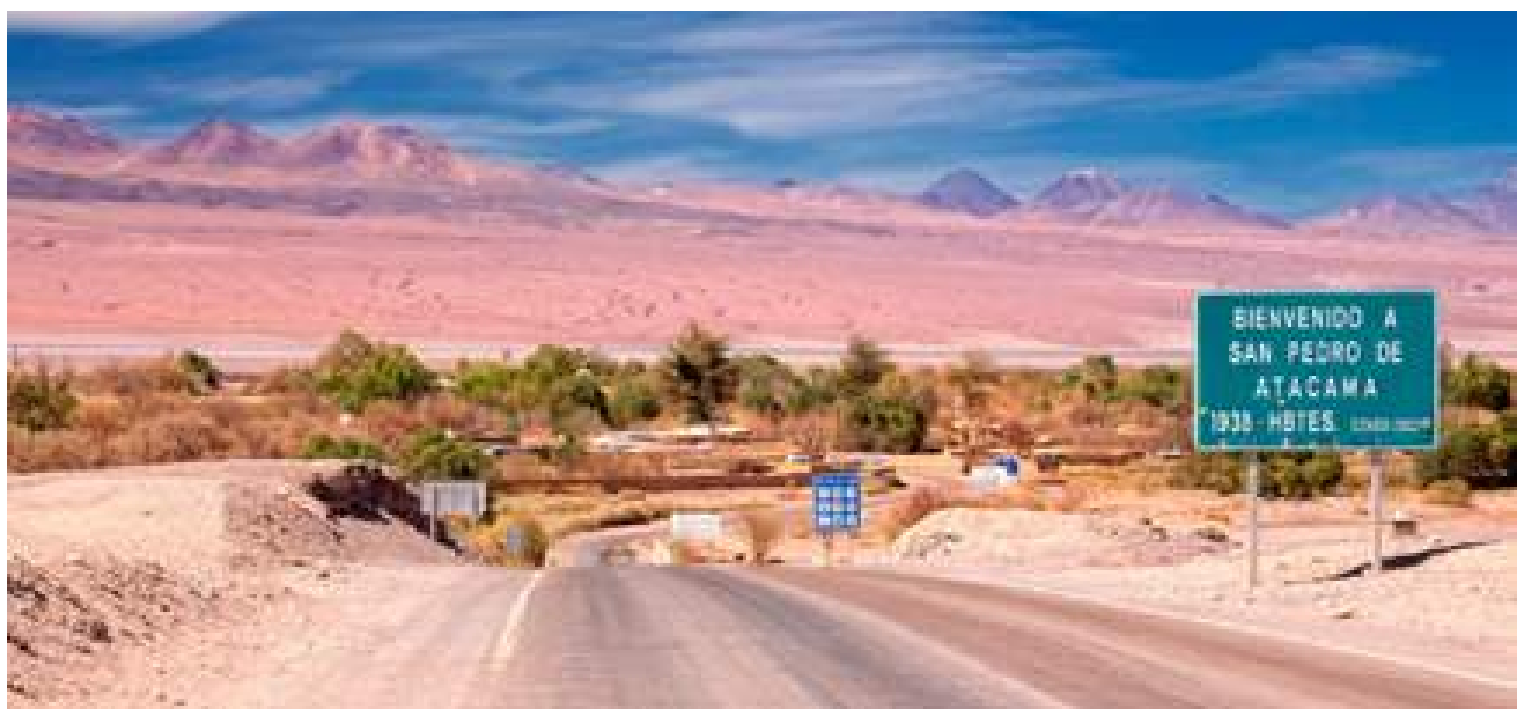

El explosivo crecimiento demográfico de las últimas décadas en San Pedro de Atacama está asociado al crecimiento vegetativo, la retención de población y la migración desde otras zonas del país que genera la actividad turística. Ello ha implicado la construcción de aproximadamente dos mil nuevas viviendas en los últimos quince años (2002-2017). En los ayllus se puede apreciar el aumento de la construcción de nuevas casas, lo que ha acrecentado la densidad de la zona rural. Pero es necesario destacar que la mayoría de las viviendas construidas corresponden a poblaciones formadas fuera de los límites de los ayllus agrícolas, poblaciones que han desbordado los contornos de San Pedro de Atacama para instalarse en tierras del desierto, especialmente en el sector nororiente del pueblo.
Las nuevas poblaciones han sido construidas en los extramuros y sus siluetas ya son observables a la llegada a San Pedro de Atacama cuando se ingresa desde Calama. Al fondo, tras las copas de los árboles y el límite de la zona verde, se puede apreciar una hilera de casas de madera, precarias construcciones, muchas de ellas producto de "tomas de terreno" ocurridas en los últimos años. Entre estas antiguas y nuevas urbanizaciones de la expansión sanpedrina destacan las poblaciones Lickanantay, Conde Duque, Machuca, Punta de Diamante, El Carmen, Licancabur y Villa Los Algarrobos. Este panorama poblacional debería incrementarse debido a las numerosas familias y personas sin viviendas que habitan San Pedro de Atacama como allegados y que trabajan en torno a alguna actividad turística ${ }^{11}$. 
Figura 4. Expansión urbana en San Pedro de Atacama. Se aprecia uno de los antiguos calvarios de protección de San Pedro de Atacama ubicado en el sector oriente del pueblo y cercano a la antigua población Machuca. Años atrás, el calvario estaba en pleno desierto y detrás suyo se apreciaba todo el llano de Vilama hasta el volcán Licancabur. Esta fotografía de 2019 muestra cómo ahora estos terrenos abiertos han sido copados con nuevas construcciones urbanas.

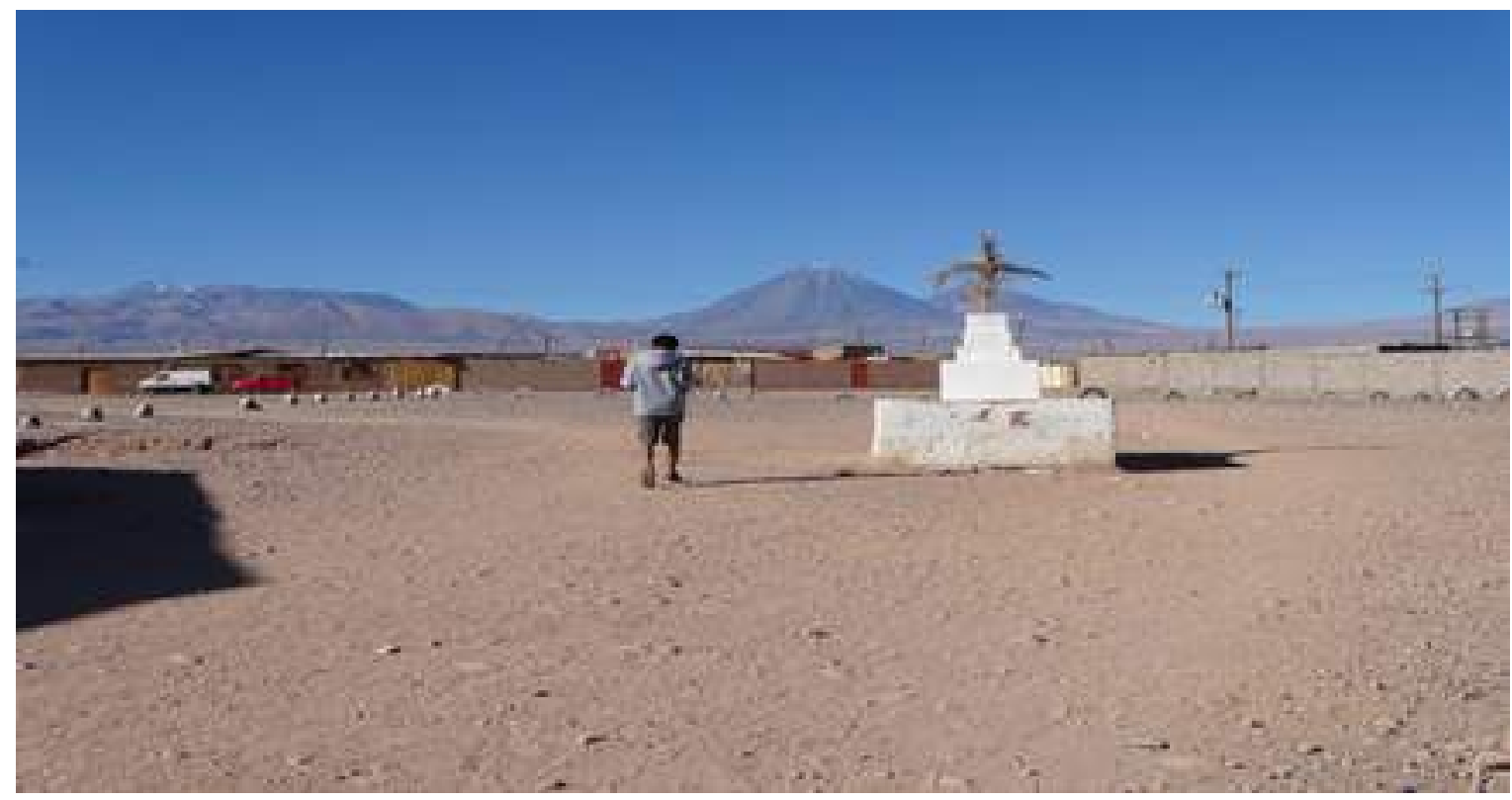

En los últimos años, los servicios básicos como agua potable y electricidad fueron mejorados ostensiblemente gracias a la presión de la industria del turismo. Hasta inicios del año 2000, San Pedro de Atacama se abastecía de agua potable traída de Toconao, Yerbas Buenas en las cercanías de Río Grande o se compraba en "chimbombos" en el comercio local. El agua de los baños y la usada en la cocina procedía de una captación con bombas de extracción desde el río Vilama y venía cargada de sales. La electricidad solo funcionaba al anochecer durante algunas horas. Pero el auge del turismo obligó a rápidos cambios para resolver la situación sanitaria y energética debido al aumento sostenido de la población permanente y de turistas.
En 2008 se produce un cambio significativo en el abastecimiento de agua potable con la construcción de una primera planta de extracción de aguas subterráneas en el llano de Vilama, tratadas con osmosis inversa. En 2013, la planta de agua se amplió, con lo que se incrementó la disponibilidad de abastecimiento en $600 \mathrm{~m}^{3}$ por día, lo que benefició "a los más de 7 mil sanpedrinos y otros 4 mil que forman parte de la población flotante del poblado" (El Diario de Antofagasta, 2013), es decir, una población de once mil personas. Sin embargo, el abastecimiento que parecía resuelto en 2013 , en la actualidad está nuevamente en crisis debido al aumento de la población local y de turistas. Por ello, es común escuchar a los sanpedrinos que los fines de semana largos o los inicios de vacaciones 
se debe acumular y guardar agua en las casas debido a la gran afluencia de turistas que reduce el suministro, por lo que este suele escasear. En cuanto a la electricidad, San Pedro de Atacama contaba hasta la década de 1990 con energía durante algunas horas de la noche y los hoteles y otros establecimientos tenían sus propios equipos generadores. Recién a mediados de esa década se logró ampliar a 15 horas al día la disponibilidad de electricidad con la instalación de un equipo de generación diésel. Finalmente, en noviembre de 2002 un diario anunciaba "San Pedro de Atacama tendrá electricidad todo el día" (El Mercurio de Antofagasta, 2002).

Se configura así la imagen actual de San Pedro de Atacama formada por un centro atiborrado por el comercio establecido en torno al turismo, con sus calles repletas de visitantes y locales de tours operadores. En los ayllus aparece un proceso de gentrificación rural, con la venta de tierras atacameñas, el aumento de la densidad de viviendas y la construcción de nuevos hoteles y alojamientos. Y, finalmente, emerge un área de expansión urbana sobre tierras del desierto que sostiene a las nuevas poblaciones. San Pedro de Atacama, hoy en día, presenta todos los problemas y los beneficios de una pequeña urbe que ha sido y seguirá siendo transformada por el turismo y la afluencia de visitantes, quienes ignoran cada vez más la cultura atacameña y arriban en busca de paisajes y experiencias estéticas personales.

\section{Turismo del paisaje y desconocimiento de la cultura atacameña}

San Pedro de Atacama recibe todos los días a más y más turistas que llegan para conocer un listado de lugares promovidos como destino o atractivos turísticos por los sitios web de empresas de turismo, los hoteles o las instituciones del Estado. Los turistas que arriban comen, pasean y compran en el pueblo y alojan en hoteles, hostales u alojamientos de diversa calidad, la mayoría localizados en el down town o en los ayllus cercanos. Todos vienen a conocer los destinos ofrecidos, pero estos no están en el centro del pueblo, sino fuera del radio de San Pedro de Atacama. En el medio de este están localizadas las oficinas de los tours operadores, que son los encargados de conducir a los visitantes a los diversos lugares ofertados. A su llegada se les pregunta siempre cuántos días estarán en San Pedro de Atacama, para luego venderles visitas a lugares relacionados con lagunas, géiseres y sitios geológicos.

Tanto el pucará de Quitor y la aldea de Tulor y los demás lugares de atracción turística están situados en territorios de comunidades atacameñas, a unos pocos o más de cien kilómetros de distancia de San Pedro de Atacama. Para acceder a lugares como el Valle de la Luna, los géiseres del Tatio o las lagunas altiplánicas es imprescindible contar con movilización y guías. Este servicio lo proporcionan las agencias de turismo y los tours operadores, la mayoría empresas no atacameñas. Las salidas de los tours operadores con turistas desde San Pedro de Atacama a los lugares de visita constituyen el primer desborde de los visitantes hacia los territorios de comunidades atacameñas, donde la venta de tickets es el principal ingreso económico.

San Pedro de Atacama, además de ser la zona de concentración de hoteles y restaurantes, también es el espacio colonizado por los tours operadores, los encargados de la oferta de circuitos de visitas y de la narrativa de los lugares. Muchas de estas empresas seducen a 
los turistas con relatos sobre lo que pueden ver, hacer, sentir y vivir en los destinos ofrecidos, cuentos que conllevan un hedonismo que es parte de la estrategia para vender los paquetes turísticos a los visitantes. Luego conducen y guían a los turistas con discursos pobres, y muchas veces sin contenido, sobre el paisaje, los lugares, la cultura y la historia atacameña o simplemente omiten algún tipo de explicación.
En un estudio reciente (Molina, 2018b) se realizó una encuesta a los tours operadores de San Pedro de Atacama para conocer cuáles eran los lugares ofertados para los tres días que suelen durar las estadías de cada turista. La oferta se relacionaba con lugares vinculados con destinos a sitios naturales fáciles de vender por estar difundidos en el proceso de masificación del turismo.

Cuadro 1. Destinos de visitas: oferta de tours operadores de San Pedro de Atacama (2017)

\begin{tabular}{|l|c|}
\hline Destinos turísticos ofertados & $\begin{array}{c}\% \\
\text { tours operadores por }\end{array}$ \\
\hline 1. Valle de la Luna (RNLF) & $100 \%$ \\
\hline 2. Géiseres del Tatio & $100 \%$ \\
\hline 3. Salar de Tara y Piedras Monjes de la Pacana. & $100 \%$ \\
\hline 4. Piedras Rojas y lagunas altiplánicas: Tuyasto y salar de Tara (RNLF) & $100 \%$ \\
\hline 5. Laguna Chaxa incluida dentro de otros circuitos (RNLF) & $100 \%$ \\
\hline 6. Valle del Arco Iris, petroglifos de Yerbas Buenas & $100 \%$ \\
\hline 7. Termas de Puritama & $90 \%$ \\
\hline 8. Laguna Cejar en salar de Atacama & $90 \%$ \\
\hline 9. Laguna Tebenquiche en salar de Atacama & $40 \%$ \\
\hline 10. Laguna Baltinache en salar de Atacama & $20 \%$ \\
\hline 11. Volcanes Toco y Lascar & $25 \%$ \\
\hline 12. Astronómico & $80 \%$ \\
\hline 13. Caravana ancestral & $10 \%$ \\
\hline 14. Tour arqueológico pucará Quitor & $10 \%$ \\
\hline 15. Cosmovisión andina & $10 \%$ \\
\hline 16. Aldea de Tulor (RNLF) & $10 \%$ \\
\hline
\end{tabular}

Fuente: Elaboración propia con base en resultados preliminares del estudio FONDECYT № 1170236 (junio de 2018) (RNLF: sitios que forman parte de la Reserva Nacional Los Flamencos) (Molina, 2018b). 
Los resultados de la encuesta mostraron que el turismo masivo se basa en la visita de atractivos como el valle de la Luna, una formación geológica de la cordillera de la Sal; los géiseres del Tatio en el altiplano; la laguna Chaxa para el avistamiento de flamencos en el salar de Atacama; las lagunas Miscantes y Meñiques en la zona altiplánica; Piedras Coloradas, un lugar de reciente explotación en Socaire, y el llamado valle del Arco Iris en la zona de Río Grande. Todos ellos son ofrecidos sin distinción y de modo unánime por los tours operadores que concentran la actividad turística masiva. Luego le siguen, en orden decreciente, lugares más exclusivos, como las termas de Puritama y las lagunas saladas de Cejar, Tebenquiche y Baltinache. Sin embargo, los tours relacionados con la cultura e historia atacameña no sobrepasan el $10 \%$ de la oferta de los tours operadores (números del 13 al 16 del cuadro 1).

Por otra parte, la reducida oferta de las agencias de tours operadores de sitios históricos y de actividades culturales atacameñas evidencia que es el consumo de paisajes lo que da rentabilidad y movimiento al negocio. La cultura atacameña queda subsumida e invisibilizada, sin narrativa y alejada del interés del consumo hedonista de los turistas. Esta constatación se puede apreciar en el ingreso de visitantes a la Reserva Nacional Los Flamencos, formada por sitios naturales y por sitios culturales patrimoniales. Según la Corporación Nacional Forestal (CONAF), coadministradora con las comunidades atacameñas de los sitios que forman esta reserva, en 2015 ingresaron 253.093 visitantes. De ellos, $40 \%$ se dirigió a la laguna Chaxa para avistar aves migratorias; $30 \%$ visitó las lagunas Miscanti y Meñiques, parte de las Ilamadas lagunas altiplánicas; $24,5 \%$ de los turistas visitó el valle de la Luna, y, final- mente, solo $4.5 \%$ visitaron la aldea prehispánica de Tulor, el único destino dentro de la reserva de carácter arqueológico y cultural (Molina, 2018b).

Con un turismo basado en el disfrute de la naturaleza como una experiencia estética geográfica que desconoce la cultura atacameña se cierra el círculo de esta nueva colonización sobre el territorio atacameño. Así, a nivel urbano y rural, lo atacameño desaparece y se invisibiliza, solo queda representado por los guardaparques o el personal que administra cada lugar de visita.

Atrás quedaron los intentos de construir un turismo con identidad indígena, un turismo cultural donde la historia y la cultura atacameña fueran protagonistas. Quedó en el camino el Plan Maestro de Desarrollo Turístico de San Pedro de Atacama de 1996 que identificó 140 atractivos turísticos en los que la oferta potencial de los aspectos culturales era hegemónica. Esta propuesta comprendía 92 sitios, lugares o celebraciones de carácter cultural y 48 sitios o lugares de atractivos naturales: "la comuna de San Pedro de Atacama cuenta con la mayor cantidad de atractivos (catastrados) de la Región de Antofagasta, siendo los de mayor jerarquía las fiestas religiosas, artesanía típica, sitios arqueológicos, tambos y tambillos, lagunas y salares y el Valle de la Luna" (SERNATUR, 1996)12. El Plan Maestro de Turismo proponía la participación activa de las comunidades atacameñas del salar de Atacama en la gestión y el control territorial, pero nada de esto fue posible puesto que, al apoderarse las empresas y los empresarios del turismo del centro de San Pedro de Atacama, se controlaron los destinos y la oferta turística. Los atacameños perdieron el centro del 
pueblo y, con ello, la influencia en el control del turismo. Se replegaron a los territorios de sus comunidades, que son las zonas de destino de los visitantes, dejando la movilidad de los turistas de San Pedro de Atacama en manos de las agencias de turismo o tours operadores ${ }^{13}$.

\section{Desbordes del turismo}

San Pedro de Atacama es el lugar dormitorio de los turistas. Estos visitantes, para conocer los lugares ofertados por los tours operadores, deben ser llevados hasta los territorios de las comunidades atacameñas donde se encuentran los atractivos. En estas circunstancias los atacameños se limitan, en mayor porcentaje, a un turismo receptivo, que muchas veces consiste solo en el cobro del ticket de entrada, siendo esta la modalidad más precaria o menos desarrollada del turismo indígena (De la Maza, 2015). En estos casos las comunidades atacameñas o sus representantes son los encargados de recibir a los turistas-visitantes que arriban trasladados por los tours operadores. Estos arribos no están a salvo de los desbordes que constantemente genera una actividad turística desregulada, que en San Pedro de Atacama se ha caracterizado por un laissez faire.

Entre los desbordes más comunes de algunos tours operadores están las entradas subrepticias a territorios de comunidades, creación de caminos no autorizados, violación de la privacidad de las personas y sus residencias, desconocimiento de la cultura atacameña, apertura de cercos en sitios cerrados a los turistas, contaminación del medio ambiente y destrucción del patrimonio, todo lo cual altera las formas de vida tradicionales. Estas acciones se basan en la impericia, el menosprecio y la falta de reconocimiento de la cultura indígena atacameña y sus derechos territoriales. Numerosos son los ejemplos de lo señalado.

Uno de ellos ocurre en el pueblo de Machuca, donde cada día por la mañana bajan desde los géiseres del Tatio veinte a treinta buses medianos, repletos de turistas que pasan a tomar desayuno y comer anticuchos de carne de llama y empanadas. Durante este descanso aprovechan para visitar el pequeño pueblo que cuenta con una iglesia tradicional de doble campanario y un humedal con una alargada laguna, donde nace el río Peñaliri y abunda la avifauna nativa. La presidenta de la comunidad de Machuca denuncia:

[...] hemos observado que hay agencias que trasgreden las barreras, abren caminos con sus vehículos; turistas que a toda costa se quieren acercar a la fauna, alterando a aves y mamíferos, incluso intentan alimentarlos para poder tocarlos y fotografiarlos, lo que afecta a su dieta, hábitats y flujos migratorios. Estamos trabajando en mejorar algunos accesos a sitios de interés y miradores, pero las agencias insisten en trasgredir los límites, lo que demora aún más la habilitación de estos espacios. Solo pedimos respeto hacia nuestra comunidad, nuestras tradiciones y nuestra gente, a nadie le gusta que la fotografíen sin su permiso, mucho menos en la tranquilidad de su casa (El Mercurio de Calama, 2019a).

En la misma noticia se señala que los habitantes de Machuca están sometidos al uso de drones que afectan la tranquilidad y la privacidad de las familias, que piden que no se hagan fotografías de sus habitantes, que los visitantes no alteren ni se salgan de los caminos y senderos habilitados para las visitas, que no se ingrese a estancias y corrales de animales y que se evite la realización de fogatas que resultan una amenaza para las viviendas del 
sector. Este relato da la imagen de turistas salvajes que actúan sin ningún control de los tours operadores, choferes y guías, y trasciende que en el turismo masivo el personal carece de preparación intercultural o de sensibilidad por la cultura atacameña.

Figura 5. Algunos titulares de noticias de diarios regionales aparecidos entre los meses de julio y agosto de 2019 que denuncian la conflictiva relación entre tours operadores y comunidades atacameñas.

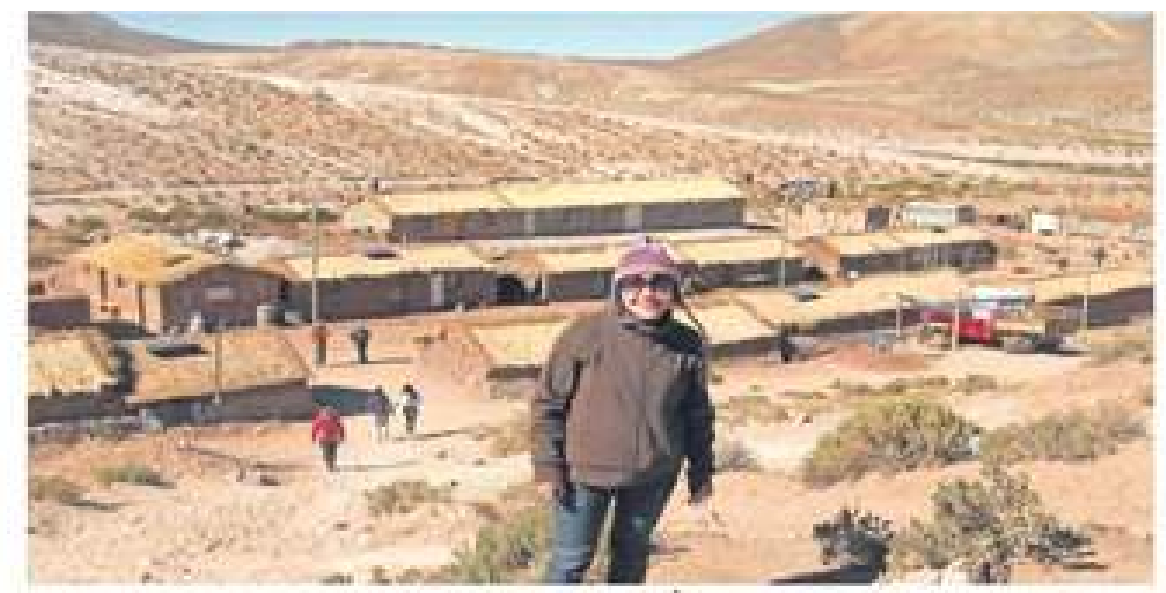

COMUNIDAD DE MACHUCA DENUNCIA INVASIÓN EN SUS PROPIEDADES

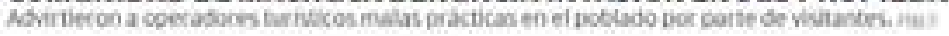

\section{Pobladores de Machuca advierten verdadera invasión de turistas a su propiedad privada}

Denuncian đañoa andas patrimontales $y$ naturates en Tocronaso

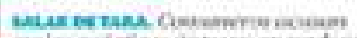

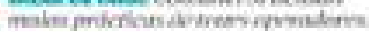

A mayor abundamiento, el desborde también llega al altiplano, al oriente de San Pedro de Atacama y en dirección al paso internacional Jama. Allí se encuentran los salares de Tara y Loyoques, que forman parte del territorio de la comunidad de Toconao. Esta denunció recientemente los daños patrimoniales y a la naturaleza provocados por las malas prácticas de los tours operadores. Uno de los representantes de la Unidad Territorial y de Medio Ambiente de la Comunidad Atacameña de Toconao, señala: "hemos constatado una serie de irrupciones irregulares al salar de Tara y otros puntos, por parte de los tours operadores, los que no han respetado el cierre de este atractivo turístico, pese a las advertencias de la comunidad. Los que ingresan por pasos no habilitados, generando suciedad, daño patrimonial y natural del sector". Enseguida agrega que: "Varias llamas han sido encontradas muertas en estos sectores [...] que afectan directamente la tradición pastoral de nuestros comuneros". Para mayores antecedentes, precisa que: 
[...] en el lugar (Loyoques y Salar de Tara) es posible encontrar refugios usados por pastores durante todo el año, corrales donde descansa el ganado, parguas usadas como bodegas para almacenar forraje y sitios arqueológicos, incluyendo gentilares donde descansan nuestros abuelos. Es en estos lugares tan llenos de identidad y de gran importancia para nuestra cosmovisión, es donde se han encontrado residuos plásticos, bolsas de basura, papel higiénico, fecas humanas y destrucción de sitios arqueológicos.

Termina denunciando que "La fiscalización es inexistente, y las malas prácticas de inescrupulosos que están afectando de forma negativa nuestro patrimonio natural, cultural y la biodiversidad de nuestros territorios ancestrales" (EI Mercurio de Calama, 2019b).

Las agencias turísticas y los tours operadores organizados en diferentes agrupaciones en San Pedro de Atacama, entre ellas la Cámara de Turismo de San Pedro de Atacama y la Asociación de Pro Guías de la comuna, se pronuncian sobre las denuncias argumentando que se trata de "agencias informales" y que los daños al ganado "deben ser investigados por las instituciones correspondientes", deslindando su responsabilidad de "aquellos inescrupulosos que no se detienen a pensar en el impacto que generan sus malas prácticas al turismo sustentable" y exigiendo la presencia y la acción de las autoridades (Estrella del Loa, 2019). Sin embargo, es posible enunciar que la motivación de estas actuaciones es una cuestión más profunda, relacionada con el desconocimiento de los derechos territoriales de las comunidades atacameñas por parte de los tours operadores que controlan la demanda turística y el traslado hacia los atractivos. Ahora argumentan a su favor con derechos constitucionales, convirtiendo el territorio indígena en un campo de disputa con las comunidades ataca- meñas. Esta contradicción entre tours operadores y comunidades atacameñas quedó develada con ocasión del cierre del destino turístico Piedras Rojas por parte de la comunidad de Socaire.

En enero de 2018, esta comunidad atacameña cerró el acceso a uno de los destinos más promocionados por los tours operadores, las llamadas lagunas altiplánicas o Piedras Rojas, localizadas dentro del salar de Aguas Calientes en territorio de Socaire, a unos $4.000 \mathrm{msnm}$, y ubicadas a 150 kilómetros de San Pedro de Atacama. Las razones del cierre fueron, primero, la pintura de las rocas con spray, y, luego, hecho que colmó la paciencia de los comuneros, observar a un turista realizar kitesurfing sobre la laguna del salar, deporte que combina el surf con un parapente para deslizarse sobre el agua mediante una tabla. Este incidente destapó una de las contradicciones socioeconómicas y étnicas más claras que se han encubado en el último tiempo con la expansión del turismo en San Pedro de Atacama: la disputa territorial.

En efecto, las comunidades atacameñas delimitaron en la década de 1990 sus territorios ancestrales en virtud de un mandato de la Ley Indígena 19.253, posesión territorial que fue reconocida y afirmada por el Convenio 169 de la Organización Internacional del Trabajo (OIT), que reconoce la existencia de los territorios de indígenas (Datura, 2000). En virtud de la ocupación ancestral, las comunidades han establecido un control territorial que les permite establecer medidas para la sustentabilidad y la preservación del medio ambiente cultural y natural. Sin embargo, estos derechos indígenas son cuestionados por los nuevos colonizadores, los tours operadores, que citan la Constitución de la República de Chile para defender sus 
intereses: "Con estas acciones [las realizadas por la comunidad de Socaire] se coarta nuestra libertad de trabajo y libre tránsito por las carreteras internacionales de nuestro país, como lo garantiza la Constitución. Toda persona tiene derecho de residir y permanecer en cualquier lugar de la República, trasladarse de uno a otro, entrar y salir de su territorio" (El Chululo, 2018).

Más allá de la inconsistencia de esta argumentación observada desde la perspectiva de los derechos indígenas y de la legislación común, lo que hay de fondo es una disputa territorial entre turismo y comunidad atacameña. Esta situación supone, de parte de los tours operadores, un implícito desconocimiento de los derechos territoriales de las comunidades. Por ello, no evitan calificar el acontecimiento diciendo: "Manifestamos nuestro total rechazo a la medida arbitraria que está tomando la comunidad de Socaire, al bloquear un camino público que dirige hacia Aguas Calientes o Piedras Rojas, esto en el kilómetro 134. [...] Esto nos está afectando, debido a que Chile vende su imagen país y al llegar el turista se encuentra con esto, claramente deja mucho que desear", precisa el representante de los operadores turísticos de San Pedro de Atacama (El Chululo, 2018).

El panorama actual de la colonización-invasión del turismo desregulado, con poca presencia de la autoridad y con un accionar por sí y ante sí de los operadores turísticos de San Pedro de Atacama en los territorios de comunidades de la cuenca del salar, ha generado respuestas diferenciadas por parte de las comunidades atacameñas. Una es la que intenta poner barreras y regulaciones, promoviendo el respeto por la cultura atacameña y los territorios de comunidades; la otra es la estrategia adaptativa y rentista vinculada a la indus- tria del turismo sanpedrino.

\section{Conclusiones}

Como recapitulación de las nostalgias, las conversiones y los desbordes en San Pedro de Atacama, las observaciones etnográficas y la información recopilada en diversas fuentes muestran que la expansión del turismo ocurrida en las últimas décadas ha generado cambios profundos en cuatros espacios: el centro del pueblo o down town, los ayllus, la periferia desértica inmediata y los territorios de las comunidades de la cuenca del salar de Atacama.

El centro histórico del pueblo, anterior residencia de los atacameños y de los servicios y las sedes comunitarias locales, se ha despoblado de sus antiguos moradores para transformarse en un espacio mayormente ajeno a los pobladores originarios, aunque los inmuebles son, en gran parte, rentados por ellos. Así, en este espacio el turismo y los servicios asociados son funcionales a la acumulación rentista indígena local. La invasión de tiendas de servicios al turismo sigue expandiendo cada vez más su radio y cambiando el uso residencial por el comercial. El control del centro sanpedrino por el turismo, y especialmente por tours operadores, ha significado que los destinos y la movilidad turística esté regentada por estas empresas y en ningún caso por atacameños. La población indígena local, los atacameños, tienen tres categorías de inserción respecto del turismo: son rentistas o pequeños empresarios, son trabajadores de apoyo y servicio en la industria del turismo o son administradores de los sitios de destino a los que llevan a los turistas, pero la característica que atraviesa a este rubro en San Pedro es que la cultura atacameña ha desaparecido o ha sido invisibilizada en la práctica. El pueblo se ha transformado en 
un centro urbano con las mismas tiendas de un mall de la ciudad de Santiago o de Antofagasta, a las que se suman abundantes oficinas de tours operadores, numerosos restaurantes, algunas farmacias, bancos y almacenes, y diferentes locales de souvenirs.

En el caso de los ayllus, estos se han transformado en lugares donde se concentra la oferta de tierras atacameñas para destinarlas a usos residenciales o construcción de hoteles o de alojamiento varios, con lo cual se soslaya la Ley indígena. En los terrenos agrícolas de los ayllus aún en poder de atacameños se desarrollan escasamente cultivos y sus tierras siguen siendo más bien una oferta para la expansión del mercado hotelero. En el caso de las poblaciones de reciente data, estas son producto del aumento explosivo de la población, principalmente de migrantes locales, nacionales y algunos extranjeros, que han desbordado los antiguos límites del poblamiento. Se trata de una expansión urbana fuera de los ayllus y sobre el desierto, donde hoy se concentra la mayor parte de la población de San Pedro de Atacama. Estos nuevos asentamientos dan una imagen de poblaciones pobres, un paisaje urbano impensado décadas atrás, donde en muchos casos existen propietarios de viviendas obtenidas después de una toma de terrenos que pasan a ser segunda propiedad y que destinan al arriendo.

Entre otros desbordes, en San Pedro de Atacama destaca la actuación de tours operadores que han invadido terrenos de comunidades, afectando el patrimonio, la cultura, el medioambiente y la vida cotidiana, y que incluso han llegado a disputar a los antiguos habitantes indígenas sus derechos territoriales.
Finalmente, respecto de la cultura y la historia atacameña, esta quedó sepultada en las narrativas de los atractivos turísticos. Hoy los visitantes concurren en su gran mayoría a los sitios ofertados por los tours operadores que solo destacan el disfrute del paisaje y la experiencia estética carente de cualquier asomo a la cultura atacameña. Esto favorece iniciativas insólitas, pero admitidas y toleradas en el laissez faire atacameño del turismo. Así, es posible, cuando usted visite San Pedro de Atacama, contratar un "tour ufológico" para visitar una supuesta civilización de "lémures" y "huellas de gigantes mitológicos" y, a la vez, ganarse un trozo de meteorito de manos de los dueños de la empresa, ello si logra avistar un "ovni". Por cierto, al parecer resulta una invitación más entretenida que visitar el valle de la Luna, atestado de cientos de viajeros. Así es el panorama del turismo en San Pedro de Atacama: lleno de nostalgias, conversiones y desbordes.

La descripción anterior muestra la desregulación del turismo, la política de laissez faire que se ha aplicado y la falta de planificación y de intervención de las autoridades en San Pedro de Atacama. Esta desregulación es expresión de la salvaje expansión del turismo que ha conllevado beneficios y condenas para los atacameños. Por ahora es fácil avizorar que en adelante el turismo desregulado y feroz comenzará a encontrarse con más incidentes y dificultades. No sabemos si este tipo de turismo entrará en crisis terminal, pero no tiene buen futuro. La masividad del turismo, la invasión de visitantes, la insustentabilidad cultural y ambiental, la acumulación compulsiva de capital y la presión sobre las comunidades atacameñas puede terminar por darle un golpe mortal a este tipo de turismo, o este tipo de turismo arrastrar hasta la decadencia al territorio atacameño. 


\section{Notas}

${ }^{1}$ En la década de 2000 se inició el boom turístico y el inicio explosivo de la afluencia de visitas a San Pedro de Atacama. Este era un pueblo tranquilo hasta la década de 1980, pero ya a fines los años noventa su pasividad rural era alterada con las borracheras de los visitantes, los gritos y los cantos durante la noche, manifestaciones que interrumpían el descanso nocturno de los pobladores que aún mantenían sus viviendas en el centro del pueblo. Para controlar estos desbordes y por acción de los propios moradores atacameños, la municipalidad local dictó el 23 de abril de 2008 la Ordenanza № 03 sobre patente de alcoholes y horarios de funcionamiento de establecimientos de expendio de bebidas alcohólicas, que determinó para San Pedro de Atacama el horario para restaurantes y locales de venta de alcoholes entre las 7:00 am y las 2:00 am, por tanto, deben permanecer cerrados entre las 2:00 de la madrugada y las 7.00 de la mañana. El artículo 10 de la Ordenanza rezaba lo siguiente: "Considerando que la comuna, en todas sus zonas, tiene carácter eminentemente turístico; por medidas de seguridad ciudadana y en resguardo de la tranquilidad de los vecinos y turistas -objetivo primordial de la gestión municipal- se hace necesario fijar horarios diferenciados de funcionamiento a los establecimientos de expendio de bebidas alcohólicas para ser consumidas dentro o fuera del local de venta que se indican".

${ }^{2}$ Una noticia publicada en mayo de 2018 titula: "El fantasma de la 'turismofobia' llega a San Pedro de Atacama [...] La capital arqueológica y turística de Chile, San Pedro de Atacama, es uno de los centros de mayor interés de los visitantes extranjeros en nuestro país, al igual que Torres del Paine e Isla de Pascua. De acuerdo a los entendidos en la materia, si no se toman medidas concretas en estos lugares, podrían formar parte del fenómeno de la 'turismofobia'. Esta situación es la que se vive actualmente en conocidas ciudades europeas como Ámsterdam, Venecia o Barcelona, donde los residentes deben convivir con una gran cantidad de turistas que no siempre respetan las costumbres y tradiciones de los ciudadanos" (El Mercurio, 2018).

${ }^{3}$ El centro de San Pedro de Atacama se transformó considerablemente. Por ejemplo, en la esquina de la calle Toconao con Caracoles, donde actualmente se localiza una farmacia Cruz Verde, existió antes una agencia de turismo y en los años noventa y principios de 2000 estuvo el Tambo Atacameño, un emblemático local de música andina de carácter intercultural e interétnico, donde se reunían atacameños y afuerinos a cantar y bailar música andina. Era una fiesta diaria que duraba hasta la madrugada. Estos locales interculturales e interétnicos se acabaron en San Pedro de Atacama. Solo en algunos restaurantes más alejados del centro es posible aún encontrarse con algunos atacameños y con toconares con sus sombreros y largas trenzas.

${ }^{4}$ La actividad turística tiene periodos de alta y baja temporada. En San Pedro de Atacama en los meses de mayo y junio decrece la afluencia, pero en julio y los meses sucesivos comienza un sostenido aumento. En octubre de 2015, San Pedro de Atacama registró la tasa de ocupación más alta del país en alojamientos turísticos. Este destino fue el más visitado a nivel nacional por turistas nacionales y extranjeros durante el fin de semana del 12 de octubre, fecha en que logró una ocupación de 90\% respecto de años anteriores. La tasa de ocupación creció 6,9\% (El Mercurio de Calama, 20 de octubre, 2015).

${ }^{5}$ Entre los hoteles cinco estrellas que se han instalado en las tierras agrícolas de San Pedro de Atacama se encuentran, según la revista Chululo de San Pedro de Atacama, publicada el 18 de julio de 2011, los siguientes hoteles, con sus dueños y características: "Hotel Explora, ligado al empresario Pedro lbáñez, fue el primero que se inauguró en San Pedro de Atacama, en 1998. La tarifa para tres noches es US\$1.980 por persona. Cuenta con 50 habitaciones. Hotel Tierra Atacama los socios son los Matetic, Tim y Michael Purcell, Carlos Ingham y Daniel Yarur. Se abrió en 2007 y tiene 32 habitaciones. La tarifa por tres noches es US\$1.390 por persona. Hotel Alto Atacama, ligado a la familia Schiess, a Toronto Trust y Andrés Mac-Lean. El precio de tres noches, en habitación doble, es US\$1.339 por persona. Se inauguró en 2007 y tiene 32 habitaciones. Hotel Kunza, es el más grande del segmento lujo, con 60 habitaciones. Abrió en 2008. La tarifa por tres noches es US\$1.744 por persona, según su página web. Ligado a Alejandro Pérez. Hotel Awasi, la dueña es la empresaria española Ana Sainz de Vicuña. El programa de tres noches en la habitación más barata tiene un precio de US\$1.887 por persona, todo incluido" (El Chululo, 2011).

${ }^{6}$ Según un estudio de Bolados (2014), los inversionistas hoteleros son locales y foráneos a San Pedro de Atacama: "[el Hotel] Atacama Desert y el LODGE Terrantai perteneciente a un empresario atacameño. Luego nacieron durante los 90 el hotel Tulor perteneciente a una arqueóloga, el hotel Kimal de otro empresario de la región, el hotel Aldea de un ex consejero regional y la casa de Don Tomás. En los últimos años llegaron otros hoteles de cinco estrellas como fue el Kunza, Alto Atacama y el Awasi” (p. 237).

7 "En mayo de 2017, Luis Delfín Rodríguez (51) decidió llevar su caso de venta de tierras a la justicia. Nunca quedó muy convencido del valor que tenían los terrenos que vendió a la sociedad Valles del Sur S.A. ubicados en el ayllu de Beter, en San Pedro de Atacama. De acuerdo al Registro del Conservador de Bienes Raíces de Calama, en diciembre de 2016 la compañía le compró el lote № 30, de una superficie de 4,96 hectáreas, por cinco millones de pesos. El abogado José Miguel Carrasco, quien entonces trabajaba en la municipalidad de San Pedro de Atacama, patrocinó a Delfín en la causa y, según la información comercial que presentó ante el Primer Juzgado de Letras de Calama, a la fecha de la venta el precio de las tierras no debía ser inferior a 396 millones de pesos. Carrasco presentó una demanda por lesión enorme en contra de la empresa por no pagar el precio justo por un terreno que tiene un alto valor arqueológico y patrimonial. Desde ahí que se mantiene un proceso judicial en el que la empresa se ha acercado a Luis Delfín para ofrecerle un 
pago entre 60 y 100 millones de pesos, lo que aún estaría muy por debajo de la tasación comercial de esos predios" (Figueroa, 2018).

${ }^{8}$ Véase http://www.tatamallku.cl/.

${ }^{9}$ Una noticia publicada por Soychile.cl, fechada en agosto de 2019, recuerda a las mujeres atacameñas: "Durante esta jornada se dio a conocer el fallecimiento de Amelia Mamani Charcas, mujer atacameña que es recordada por caminar junto con Sonia Ramos Chockobar desde San Pedro de Atacama hasta Santiago, para intentar entrevistarse en el 2009 con la Presidenta Michelle Bachelet en defensa del Tatio. A pesar del arduo camino recorrido por ambas mujeres, que en dos semanas lograron arribar hasta la capital del país, se recuerda que la Mandataria nunca las atendió en La Moneda" (Soychile, 2019).

${ }^{10}$ La masa ganadera a inicios de la década de 1960 se componía de 8.161 ovinos, 1.482 caprinos, 438 asnales, 478 porcinos, 319 llamos, 112 mulares y 143 bovinos (Aranda, 1964), pero en 2008, esta había descendido considerablemente, puesto que solo se contaban 530 ovinos, 170 porcinos, 162 caprinos, 107 equinos, 38 llamos, 30 asnos y 21 bovinos, a lo que se suman los animales menores, que suman: $18 \%$ los conejos y $14 \%$ las gallináceas sobre el total del ganado (INE, 2007; Pérez, 2008).

${ }^{11}$ Entre los "comités de allegados" se encuentran los denominados: Ckaipa Inti, Allegados del Ayllu de Solor, El Tatio, Remanente, Inti Llojcimushan, Pajta Lamien y aquellos comités que esperan conseguir viviendas a través de su propia gestión y solicitando la ayuda del

\section{Referencias bibliográficas}

Aedo, H. (2011). Conflictos por el agua en los ayllus de San Pedro de Atacama, II Región. (Tesis de memoria de geografía). Facultad de Arquitectura y Urbanismo, Universidad de Chile, Santiago de Chile.

Aranda, X. (1964). San Pedro de Atacama: elementos diagnósticos para un plan de desarrollo local. Informaciones Geográficas, (XI-XIV), especial, 19-61.

Aranda, X., Barahona, R. \& Saa, R. (1968). Elementos diagnósticos para un plan de desarrollo local en San Pedro de Atacama. Corporación de Fomento de la Producción, Universidad de Chile, Santiago.

Bolados, P. (2014). Los conflictos etnoambientales de "Pampa Colorada" y "El Tatio" en el Salar de Atacama, Norte de Chile: procesos étnicos en un contexto minero y turístico transnacional. Estudios Atacameños, (48), 228-248.

Bustos, A. (2005). Hacia un turismo intercultural: el caso atacameño. LIDER, 13(10), 133-150.

Cerri, D. (1993 [1903]). El territorio de los Andes (República Argentina). Reseña geográfica descriptiva. Jujuy: Universidad Nacional de Jujuy (Serie Jujuy en el Pasado).

CINPRO Consultores (1997). Ordenamiento catastral de las comunidades indígenas del Altiplano de la II Región, Provincia
Estado, como el Comité de Vivienda El Tatio, Suyay Can, Kunza Turi y Lickanantay (El Chululo, 2011b).

${ }^{12}$ Entre los atractivos turísticos-culturales se nombraban a los pueblos del salar, la producción artesanal, las fiestas religiosas, las fiestas de limpias de canales, la arquitectura histórica, de iglesias y campanarios, los sitios de arte rupestre, las aldeas de culturas prehispánicas, los tambos incaicos, el paisaje rural de los ayllus y quebradas cultivadas, las rutas troperas y la presencia del Museo de Arqueológico y Etnográfico R. P. Le Paige. A su vez, entre los atractivos naturales se nombraban a los volcanes (Lascar, Licancabur, Putana, Jauna, Sairecabur, Socompa), sitios de interés geológico (valle de la Luna y valle de la Muerte), ríos (Puritama, San Pedro), salares (Atacama, Capur, Incahuasi, Pujsa, Pular, de Talar, de Tara, Quisquiro, Aguas Calientes), lagos y lagunas, termas, géiseres, quebradas $\mathrm{y}$ formaciones vegetacionales.

${ }^{13}$ La pérdida del control del centro del pueblo por los atacameños, lugar estratégico porque allí se concentran los turistas, significó que los destinos turísticos quedaron ofertados y controlados exclusivamente por empresas de tours operadores y el cobro de entradas a los sitios en manos de las comunidades atacameñas. Pero estas empresas turísticas presentan poco interés en el conocimiento de la cultura atacameña, con lo que se ha perdido la efectividad discursiva y han desaparecido los contenidos que alguna vez sustentaron la relación atacameña entre cultura y naturaleza.

de El Loa. Informe final. Preparado para la División del Catastro Nacional de Bienes del Estado del Ministerio de Bienes Nacionales, Santiago, Chile.

Cipolletti, M. (1984). Llamas y mulas, trueque y venta: el testimonio de un arriero puneño. Revista Andina, 2(4), 513-538.

Conti, V. (2003). El norte argentino y Atacama: flujos mercantiles, producción y mercados en el siglo XIX. En Benedetti, A. (Comp), Puna de Atacama: sociedad, economía y frontera (pp. 21-52). Córdoba: Alción.

Datura (2000). Propuesta de estatuto especial para la conciliación de intereses de las comunidades indígenas y de la CONAF en áreas protegidas de la provincia del Loa, II Región. Documento.

EI Chululo (2011a). La coyuntura que afecta a los hoteles de lujo en San Pedro de Atacama. 18 de julio. Recuperado de http://www. chululo.cl/pages/noticias2.php?id=19072011_022912

(2011b). Elección del Consejo Comunal de Organizaciones de la Sociedad Civil. 22 de septiembre. Recuperado de http://www. chululo.cl/pages/reportajes2.php?id=23092011_013954

(2018). Impiden a los turistas el libre acceso al sector de Aguscalientes. 11 de enero. Recuperado de http://www.chululo.cl/ pages/recortes2.php?id=10032018_035747 
El Diario de Antofagasta (2013). San Pedro de Atacama cuenta con renovado sistema de agua potable. 26 de mayo. Recuperado de http://www.diarioantofagasta.cl/regional/22624/san-pedro-de-atacama-cuenta-con-renovado-sistema-de-agua-potable/

EI Mercurio (2018). El fantasma de la "turismofobia" llega a San Pedro de Atacama. 17 de mayo. Recuperado de https://www.emol. com/noticias/Nacional/2018/05/17/906491/San-Pedro-de-Atacama-trabaja-en-un-plan-para-evitar-la-turismofobia.html

El Mercurio de Antofagasta (2002). San Pedro de Atacama tendrá electricidad todo el día. 21 de noviembre. Recuperado de http://www.emol.com/noticias/nacional/2002/11/21/99021/san-pedro-de-atacama-tendra-electricidad-todo-el-dia.html

EI Mercurio de Calama (2019a). Pobladores de Machuca advierten verdadera invasión de turistas a su propiedad privada. 12 de julio, p. 3 . Recuperado de http:/www.mercuriocalama.cl/impresa/2019/07/12/papel/ (2019b). Denuncian daño a zonas patrimoniales y naturales en Toconao. 6 de agosto, p. 4. Recuperado de http://www.mercuriocalama.cl/impresa/2019/08/06/papel/

Estrella del Loa (2019). Tours operadores esperan mayor fiscalización, 9 de agosto, p. 2. Recuperado de http://www.estrellaloa.cl/ impresa/2019/08/09/papel/

Figueroa, N. (2018). El negocio de compra de tierras indígenas de la nieta de los fundadores de Falabella en San Pedro de Atacama. El Desconcierto, 4 de diciembre. Recuperado de https://www.eldesconcierto.cl/2018/12/04/el-negocio-de-compra-de-tierras-indigenas-dela-nieta-de-los-fundadores-de-falabella-en-san-pedro-de-atacama/

García, J., Guitart, N., Pitarch, A. \& Vallvé, O. (2018). De la turismofobia a la convivencia turística: el caso de Barcelona. Análisis comparativo con Ámsterdam y Berlín. ARA, Journal of Tourism Research/Revista de Investigación Turística, 8(2), 25-34.

García, S., Rolandi, D., López, M. \& Valeri, P. (2002). Viajes comerciales de intercambio en el departamento de Antofagasta de la Sierra, Puna meridional argentina: pasado y presente. REDES, Revista Hispana para el Análisis de Redes Sociales, 2(5), mayo.

Gundermann, H. (2004). Inicios de siglo en San Pedro de Atacama: procesos, actores e imaginarios en una localidad andina. Chungara, Revista de Antropología Chilena, 36(1), 221-239.

Gundermann, H. \& González, H. (1995). Tierra, agua y sociedad atacameña, un escenario cambiante. En Pourrut, P. \& Núñez, L. (Eds.), Agua, ocupación del espacio y economía campesina en la región atacameña: aspectos dinámicos (pp. 78-106). Antofagasta: Universidad Católica del Norte.

INE (2007). Censo Agropecuario 2007. Instituto Nacional de Estadísticas, Chile.

(2012). Censo de Población y Vivienda 2012. Instituto Nacional de Estadísticas, Chile.

(2015). Proyección de población 2015. Instituto Nacional de Estadísticas, Chile.

I.M. San Pedro de Atacama (2006). Plan de Desarrollo Comunal Comuna de San Pedro de Atacama 2006-2010 (Pladeco). Primera Edición. http://bibliotecadigital.ciren.cl/bitstream/handle/123456789/6931/ SPA-HUMED01.pdf?sequence $=1$ \&isAllowed $=y$
Maza, F. de la (2015). State Conceptions of Indigenous Tourism in Chile. Annals of Tourism Research, (56), 8095.

Milano, C. (2018). Overtourism, malestar social y turismofobia: un debate controvertido. Pasos, Revista de Turismo y Patrimonio Cultural, 16(3), 551-564.

Molina, R. (2011). Los otros arrieros de la Puna y el desierto de Atacama. Chungara, Revista Chilena de Antropología, 43(2), 177-187. (2013). Cordillera de Atacama: movilidad, frontera y articulaciones collas-atacameñas. En Núñez, A., Sánchez, F. \& Arenas, F. (Eds.), Fronteras en movimiento e imaginarios geográficos: la cordillera de los Andes como espacialidad sociocultural (pp. 189-220). Santiago: RIL, Instituto de Geografía-Pontificia Universidad Católica de Chile. (2018a). San Pedro de Atacama: turismo e impactos urbanos y socioambientales en un poblado indígena del desierto, Chile. En Actas del $1^{\circ}$ Congreso Tourscape, Málaga, febrero.

(2018 b). Cultura, paisajes y experiencias estéticas-geográficas: cambios en la movilidad del turismo en San Pedro de Atacama-Chile. En Somoza Medina, X. (Coord.), De lugar geográfico a destino turístico: análisis y gestión de los procesos de cambio generados por el turismo (pp. 37-48). España: Universidad de León, Asociación de Geógrafos Españoles.

Núñez, L. (1992). Cultura y conflicto en los oasis de San Pedro de Atacama. Santiago: Editorial Universitaria.

Oehmichen, C. \& Maza, F. de la (2019). Turismo, pueblos indígenas y patrimonio cultural en México y Chile. Pasos, Revista de Turismo y Patrimonio Cultural, 17(1), 53-64.

Pérez, E. (2008). Informe técnico de actividades temporada 2007-2008. Programa de Desarrollo Local. Municipalidad de San Pedro de Atacama, San Pedro de Atacama.

Rivera, F. (1995). El contexto histórico y social del manejo de los recursos agropecuarios en los oasis de San Pedro de Atacama. En Pourrut, P. \& Núñez, L. (Eds.), Agua, ocupación del espacio y economía campesina en la región atacameña: aspectos dinámicos (pp. 61-77). Antofagasta: Universidad Católica del Norte.

Sepúlveda I., Molina, R., Delgado-Serrano, M. \& Guerrero, J. E. (2015). Aguas, riego y cultivos: cambios y permanencias en los ayllus de San Pedro de Atacama. Estudios Atacameños, Arqueología y Antropología Surandinas, (51), 185-206.

SERNATUR (1996). Plan maestro de desarrollo turístico 1996 "Región de Antofagasta; mágica y sorprendente". Recuperado de https://www.sernatur.cl/estadisticas/

(2017). Cuadros estadísticos 2016. Recuperado de https:// www.sernatur.cl/estadisticas/

Soychile (2019). Falleció mujer atacameña recordada por caminar desde San Pedro hasta Santiago defendiendo el Tatio. 16 de agosto. Recuperado de https://www.soychile.cl/Calama/ Sociedad/2019/08/16/611111/Fallecio-mujer-atacamena-recordada-por-caminar-desde-San-Pedro-hasta-Santiago-defendiendo-el-Tatio.aspx?fbclid=IwAR3vE5u9h-itGaCc9RH2SX4dGsVJLHVyo5bUhw54dBRLISsd5_fESOZaKgk

Vilches, F., Sanhueza, L. \& Garrido, C. (2014). Arquitectura de remeseros en San Pedro de Atacama, $A R Q$, (88), 76-85. 